\title{
BMJ Open Incidence and risk factors of type 2 diabetes mellitus in an overweight and obese population: a long-term retrospective cohort study from a Gulf state
}

\author{
Dybesh Regmi, ${ }^{1}$ Saif Al-Shamsi $(1),{ }^{2}$ Romona D. Govender, ${ }^{3}$ Juma Al Kaabi ${ }^{2}$
}

To cite: Regmi D, AlShamsi S, Govender RD, et al. Incidence and risk factors of type 2 diabetes mellitus in an overweight and obese population: a long-term retrospective cohort study from a Gulf state. BMJ Open 2020;10:e035813. doi:10.1136/ bmjopen-2019-035813

- Prepublication history for this paper is available online. To view these files, please visit the journal online (http://dx.doi org/10.1136/bmjopen-2019035813).

Received 17 November 2019 Revised 16 March 2020 Accepted 03 June 2020

Check for updates

(c) Author(s) (or their employer(s)) 2020. Re-use permitted under CC BY-NC. No commercial re-use. See rights and permissions. Published by BMJ.

${ }^{1}$ Department of Family and Community Medicine, Faculty of Medicine, University of Toronto, Toronto, Ontario, Canada

${ }^{2}$ Department of Internal Medicine, College of Medicine and Health Sciences, United Arab Emirates University, Al Ain, United Arab Emirates

${ }^{3}$ Department of Family Medicine, College of Medicine and Health Sciences, United Arab Emirates University, Al Ain, United Arab Emirates

Correspondence to

Dr Saif Al-Shamsi;

salshamsi@uaeu.ac.ae

\section{ABSTRACT}

Objectives A high body mass index (BMI) is associated with risk of type 2 diabetes mellitus (DM). The United Arab Emirates (UAE) is experiencing a marked increase in obesity. Nonetheless, no data are available regarding the incidence of type $2 \mathrm{DM}$ in the high-risk adult UAE population. Therefore, this study aimed to evaluate the incidence rate and risk of developing type $2 \mathrm{DM}$ among individuals with above-normal BMI in the UAE.

Design A retrospective cohort study.

Setting Outpatient clinics at a tertiary care centre in Al Ain, UAE.

Participants Three hundred and sixty-two overweight or obese adult UAE nationals who visited outpatient clinics between April 2008 and December 2008.

Primary outcome measure Patients with type 2DM were identified based on diagnosis established by a physician or through glycated haemoglobin ( $\mathrm{HbA} 1 \mathrm{c}$ ) levels $\geq 6.5 \%$ during the follow-up period (until April 2018).

Results The overall incidence rate of type 2DM during the median follow-up time of 8.7 years was 16.3 (95\% Cl 12.1 to 21.4) cases per 1000 person-years. Incidence rates in men and women were 17.7 (95\% $\mathrm{Cl} 11.6$ to 25.9$)$ and 15.0 (95\% Cl 9.8 to 22.2) cases per 1000 personyears, respectively. Multivariable Cox proportional hazard analysis determined older age and obesity in women and pre-diabetes in men to be independent risk factors for developing type $2 \mathrm{DM}$.

Conclusions The incidence rate of type 2DM in overweight and obese UAE nationals is high. In addition to screening, current strategies should strongly emphasise lifestyle modifications to decrease $\mathrm{HbA} 1 \mathrm{c}$ and BMI levels in this high-risk population.

\section{INTRODUCTION}

A rapid worldwide increase has been observed regarding the prevalence of type 2 diabetes mellitus (DM) and obesity. The United Arab Emirates (UAE) is one of the epicentres of this epidemic. In a 2007 study, the agestandardised rates for pre-diabetes and type $2 \mathrm{DM}$ among UAE nationals were $24.2 \%$ and 29\% , respectively. ${ }^{1}$ However, in a 2019 study
Strengths and limitations of this study

- This long-term longitudinal cohort study determines the incidence rate and risk factors of type 2 diabetes mellitus in overweight and obese United Arab Emirates (UAE) nationals.

> Anthropometric and laboratory data were obtained instead of self-reported information for the classification of risk factors and identification of incident cases.

- The study's subjects were recruited from a single large public hospital's ambulatory clinics; therefore, our findings may not apply to the general UAE population.

- No data were available for review regarding additional confounders, such as family history and changes in weight and physical activity.

of young Emirati men, the age-adjusted prevalence of pre-diabetes was much higher at $41.3 \% .^{2}$ By contrast, the prevalence of type 2DM in North America and Western European countries is well below $12 \% .^{3-6}$ Notably, the number of people with type $2 \mathrm{DM}$ in the UAE is estimated to reach over two million by $2040{ }^{7}$

Overweight, defined as body mass index (BMI) between 25 and $29.99 \mathrm{~kg} / \mathrm{m}^{2}$, and obesity, defined as BMI $\geq 30 \mathrm{~kg} / \mathrm{m}^{2}, 8$ are known risk factors of type $2 \mathrm{DM}^{9}{ }^{9}$ More recently, the age-adjusted prevalence of overweight and obesity among Emirati men between the ages of 18 and 30 years was noted to be $27 \%$ and $30 \%$, respectively. ${ }^{2}$ In contrast, the corresponding prevalence in another study was $23 \%$ and $10 \%$ among young Emirati women. ${ }^{10}$ Both these studies determined increased BMI to be strongly associated with diabetes.

Both obesity and type 2DM are well-known cardiometabolic risk factors for vascular complications, such as coronary heart disease 
and peripheral vascular disease. The prevalence of these vascular diseases in the UAE is $10.5 \%$ and $11.1 \%$, respectively. ${ }^{1}$ These and other vascular-related complications have resulted in the UAE having one of the highest reported global death rates for cardiovascular disease204 per 100000 for women and 309 per 100000 for men. ${ }^{11}$

The rise in the incidence of diabetes and its complications among the UAE population has been in parallel to the economic surge, resulting in growing urbanisation and changing lifestyle habits in the country. Nevertheless, over the last decade, UAE has diverted its attention and endeavoured to curb the burden of overweight and obesity, as well as to decrease the incidence of associated conditions like diabetes. The Weqaya programme, a population-wide CVD screening programme, was initiated in $2008^{12}$ to enable individuals and healthcare providers to implement CVD preventative measures. For continued assessment of the effectiveness of these local interventions, ad hoc analysis of population data at predefined intervals over a long period is required. However, epidemiological studies on type $2 \mathrm{DM}$ in the UAE have primarily focused on its prevalence in the general population. ${ }^{1213}$ Despite having information from the Weqaya programme, data regarding the incidence of type $2 \mathrm{DM}$ among obese and overweight UAE nationals remain poorly researched. This lapse is primarily because of the significant resource investment required to conduct observational cohort studies with prolonged follow-up.

Therefore, in this long-term, longitudinal retrospective study, we aimed to calculate the incidence rate of type $2 \mathrm{DM}$ and elucidate the effects of BMI on DM risk in adult UAE nationals who are overweight and obese.

\section{METHODS}

\section{Study setting}

A retrospective electronic medical record review was performed of adult patients who presented to outpatient clinics at Tawam Hospital in $\mathrm{Al}$ Ain, UAE, between 1 April 2008 and 31 December 2008. Tawam Hospital is one of the two large government hospitals in the city of $\mathrm{Al}$ Ain and serves an estimated 60000 adult UAE nationals in the city who are overweight and obese. ${ }^{1415}$

\section{Subjects and procedures}

The study population consisted of UAE nationals who were overweight and obese, aged between 18 and 75 years, who were seen at the outpatient departments at Tawam Hospital. The inclusion criteria were patients without type $2 \mathrm{DM}$, defined as having glycated haemoglobin (HbAlc) $<6.5 \%$; patients not taking antidiabetic medications; and those with BMI $\geq 25 \mathrm{~kg} / \mathrm{m}^{2}$ at baseline. The exclusion criteria were patients with missing HbAlc data, those with a history of chronic medical conditions, such as malignancy, HIV infection, receiving steroids or immunosuppression medications, or stage 3-5 chronic kidney disease (estimated glomerular filtration rate of $\leq 59 \mathrm{~mL}$ / $\left.\min / 1.73 \mathrm{~m}^{2}\right) .{ }^{16}$ Moreover, patients who had undergone

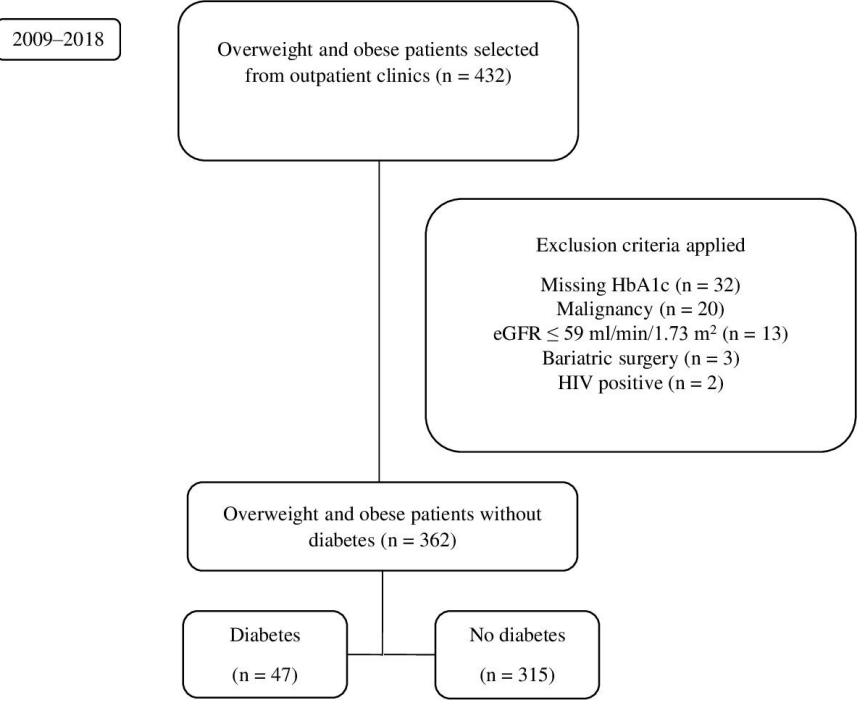

Figure 1 Flow chart for the inclusion and exclusion of patients. eGFR, estimated glomerular filtration rate; HbA1c, glycated haemoglobin.

weight reduction surgery, defined either as restrictive or malabsorptive bariatric surgery, or pharmacotherapy for weight loss were excluded from the study. The final study group consisted of 362 subjects with a BMI of $\geq 25 \mathrm{~kg} / \mathrm{m}^{2}$ (figure 1).

\section{Definitions and measurements}

Initial BMI was calculated from baseline height and weight measurements using the formula weight $(\mathrm{kg})$ divided by height squared $\left(\mathrm{m}^{2}\right)$. Overweight and obesity were defined according to the WHO classification, ${ }^{8}$ based on a BMI between 25 and $29.99 \mathrm{~kg} / \mathrm{m}^{2}$ and $\geq 30 \mathrm{~kg} / \mathrm{m}^{2}$, respectively. Hypertension (HTN) was defined as systolic blood pressure $\geq 140 \mathrm{~mm} \mathrm{Hg}$, diastolic blood pressure $\geq 90 \mathrm{~mm} \mathrm{Hg}$ or use of blood pressure medications. ${ }^{17}$ The definition of dyslipidaemia was a serum total cholesterol (TC) of $\geq 6.21 \mathrm{mmol} / \mathrm{L}$ or if the patient had a documented prescription of lipid-lowering medications. ${ }^{18}$ Prediabetes was defined as having an HbA1c level between $5.7 \%$ and $6.4 \% .{ }^{19}$ Current or history of smoking tobacco was considered a positive smoking history. Patients with a documented history of coronary heart disease, cerebrovascular disease or peripheral vascular disease were identified to have a vascular disease.

\section{Outcomes}

Our study endpoint was incident type 2DM, defined as either HbA1c $\geq 6.5 \%$ (based on the definition of DM by the American Diabetes Association) or a diagnosis of type $2 \mathrm{DM}$ established by a physician at any time during the follow-up period. ${ }^{19}$ The occurrence of incident type $2 \mathrm{DM}$ was based on a review of all the electronic medical records until 30 April 2018. All laboratory analyses were performed at the Medical Laboratory Department of Tawam Hospital. An automated analyser, Integra 400 Plus (Roche Diagnostics, Mannheim, Germany), was used to measure HbA1c levels. The HbA1c results were reported 
as percentage using the International Federation of Clinical Chemistry-National Glycohemoglobin Standardization Program master equation. ${ }^{20}$

\section{Statistical analyses}

Using a formula from Rosner, ${ }^{21}$ a sample size of 353 was calculated. This was based on the anticipated incidence of diabetes of $17.3 \%^{22}$ and using $80 \%$ power at a two-sided significance level of 0.05 . The sample size was further increased by $20 \%$ to account for patients lost to follow-up and those with missing data.

Intersex differences were determined using the MannWhitney $\mathrm{U}$ test or the independent-samples t-test for nonnormal and normal data, respectively. For categorical variables, Fisher's exact test (two-tailed) was used. Personyears at risk for incident type $2 \mathrm{DM}$ was calculated for each patient as the time from the baseline visit to the diagnosis of type $2 \mathrm{DM}$ or the most recent outpatient visit, whichever occurred first. The incidence rate of type $2 \mathrm{DM}$ with a 95\% CI was calculated per 1000 person-years by dividing the number of new cases of type 2DM by the personyears at risk. Sex-specific incidence rates were calculated stratified by age and BMI categories. Kaplan-Meier timeto-event analysis was conducted with a log-rank test to compare age and BMI categories for incident type $2 \mathrm{DM}$.

Univariable and multivariable Cox proportional hazard models were evaluated to examine predictors of incident type $2 \mathrm{DM}$ in the entire cohort and stratified by sex. The following predictor variables were examined using univariable Cox modelling: age (categorised as $<44$ years and $\geq 44$ years), sex, vascular disease, HTN, dyslipidaemia, smoking, HbAlc (categorised as $<5.7 \%$ and $\geq 5.7 \%$ ) and BMI (categorised as overweight and obese). All covariables with $\mathrm{p}<0.1$ were included in the final multivariable model. A stepwise method based on likelihood ratios, with entry and removal probabilities set at 0.05 and 0.10 , respectively, was used to check the results. The log-log plot was used to evaluate the proportional hazards assumption and was not significant. $\mathrm{P}<0.05$ was considered statistically significant. SPSS V.25 was used to analyse the data.

\section{Patient and public involvement}

There was no patient or public involvement in the design and conduct of the study.

\section{RESULTS}

\section{Characteristics of study participants}

The baseline patient characteristics of the 362 subjects are presented in table 1 . The ratio of men to women was almost 1:1. At baseline, the mean age was $44.4 \pm 14.5$ years and the BMI was $31.7 \mathrm{~kg} / \mathrm{m}^{2}$ (IQR $\left.27.6-34.2 \mathrm{~kg} / \mathrm{m}^{2}\right)$. When stratified by sex, women were older, had higher BMI and TC values, and had a higher prevalence of dyslipidaemia at baseline. Conversely, men had significantly higher baseline systolic and diastolic blood pressure values, as well as a higher prevalence of smoking history.

\section{Incidence}

After a median follow-up time of 8.7 years (IQR, 8.2-9.0 years), 47 incident cases of type $2 \mathrm{DM}$ were identified.

Table 1 Baseline characteristics of the study participants

\begin{tabular}{|c|c|c|c|c|}
\hline & $\begin{array}{l}\text { Total }(\mathrm{N}=362) \\
\text { Mean } \pm \mathrm{SD}\end{array}$ & $\begin{array}{l}\text { Men }(n=170) \\
\text { Mean } \pm \text { SD }\end{array}$ & $\begin{array}{l}\text { Women }(n=192) \\
\text { Mean } \pm \text { SD }\end{array}$ & $P$ value $†$ \\
\hline Women (\%) & 53.0 & - & - & - \\
\hline Age (years) & $44.4 \pm 14.5$ & $40.2 \pm 14.7$ & $48.1 \pm 13.2$ & $<0.001$ \\
\hline \multicolumn{5}{|l|}{ Anthropometric values } \\
\hline $\operatorname{BMI}\left(\mathrm{kg} / \mathrm{m}^{2}\right)$ & $31.7(27.6-34.2)$ & $29.6(27.3-32.8)$ & $31.2(27.9-35.8)$ & 0.001 \\
\hline SBP $(m m ~ H g)$ & $127.9 \pm 17.3$ & $129.9 \pm 17.9$ & $126.2 \pm 16.7$ & 0.040 \\
\hline $\mathrm{DBP}(\mathrm{mm} \mathrm{Hg})$ & $76.9 \pm 11.0$ & $79.0 \pm 11.3$ & $75.1 \pm 10.4$ & 0.001 \\
\hline \multicolumn{5}{|l|}{ Laboratory values } \\
\hline HbA1c (\%) & $5.6 \pm 0.5$ & $5.6 \pm 0.5$ & $5.6 \pm 0.5$ & 0.326 \\
\hline eGFR $\left(\mathrm{mL} / \mathrm{min} / 1.73 \mathrm{~m}^{2}\right)$ & $105.9 \pm 16.8(n=359)^{*}$ & $104.2 \pm 18.5(n=167)^{*}$ & $107.4 \pm 15.1$ & 0.073 \\
\hline $\mathrm{TC}(\mathrm{mmol} / \mathrm{L})$ & $5.1 \pm 0.9$ & $4.9 \pm 1.0$ & $5.2 \pm 1.0$ & 0.002 \\
\hline \multicolumn{5}{|l|}{ History of, n (\%) } \\
\hline HTN & $181(50.0)$ & $91(53.5)$ & $90(46.9)$ & 0.247 \\
\hline Dyslipidaemia & $141(39.0)$ & $52(30.6)$ & $89(46.4)$ & 0.002 \\
\hline Vascular disease & $18(5.0)$ & $10(5.9)$ & $8(4.2)$ & 0.478 \\
\hline Smoking & $56(15.5)$ & $54(31.8)$ & $2(1.0)$ & $<0.001$ \\
\hline
\end{tabular}

${ }^{*}$ The difference in $\mathrm{n}$ is due to missing data.

†Independent-samples t-test was used to calculate $p$ values for continuous variables and Fisher's exact test (two-tailed) for categorical variables.

BMI, body mass index; DBP, diastolic blood pressure; eGFR, estimated glomerular filtration rate; HbA1c, glycated haemoglobin; HTN, hypertension; SBP, systolic blood pressure; TC, total cholesterol. 


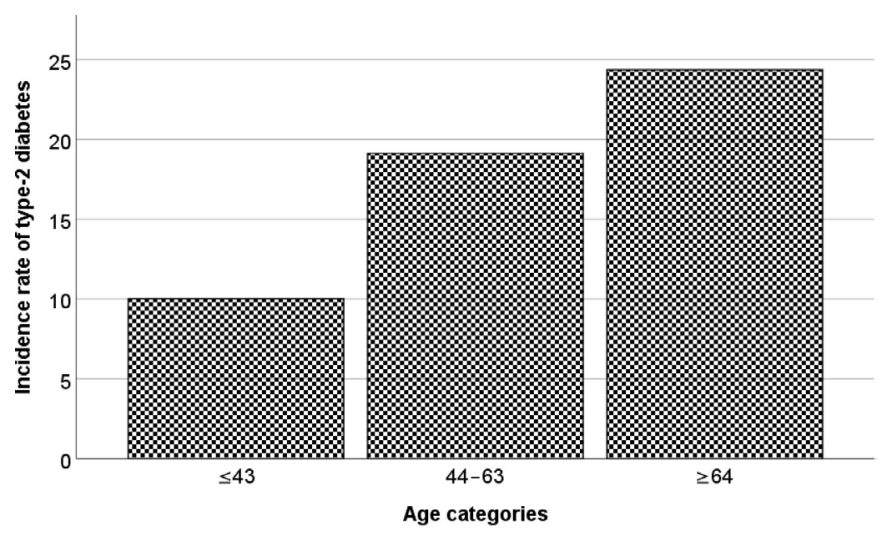

Figure 2 Overall incidence rate of type 2 diabetes mellitus (cases/1000 person-years) by increasing age.

The overall incidence rate of type $2 \mathrm{DM}$ was 16.3 (95\% CI 12.1 to 21.4) cases per 1000 person-years, and the crude incidence over the same period was $13.0 \%$ (95\% CI 9.8 to $16.8 \%$ ). The incidence rate of type $2 \mathrm{DM}$ increased with patient age (figure 2). When stratified by sex, the incidence rates were 17.7 (95\% CI 11.6 to 25.9 ) and 15.0 (95\% CI 9.8 to 22.2) cases per 1000 person-years in men and women, respectively.

Sex-specific incidence rates, as stratified by BMI, were higher in obese women (21.1, 95\% CI 13.3 to 32.0 cases per 1000 person-years) compared with overweight women (5.1, 95\% CI 1.3 to 14.0 cases per 1000 personyears $)(p=0.013)$. Incidence rates for type $2 \mathrm{DM}$ were higher in older women $(21.3,95 \%$ CI 13.5 to 31.9 cases per 1000 person-years) compared with younger women (3.7, 95\% CI 0.6 to 12.2 cases per 1000 person-years) $(p=0.008)$ (figure 3). However, these differences were not significant among men.

\section{Analyses of risk factors}

We used multivariable Cox regression analyses to examine the association of age, sex, vascular disease, dyslipidaemia, smoking, HTN, BMI and HbAlc levels with the risk of developing type $2 \mathrm{DM}$ in the entire study cohort, as well as between men and women. When adjusted for all other variables, we observed that in men an HbA1c level $\geq 5.7 \%$ ( $\mathrm{HR}=3.02,95 \% \mathrm{CI} 1.20$ to 7.62 ) and in women age $\geq 44$ years (HR=4.84, 95\% CI 1.13 to 20.73 ) and obesity (HR=3.42, 95\% CI 1.01 to 11.57$)$ were significant risk factors for the development of type 2DM (table 2).

\section{DISCUSSION}

The results of this study revealed that the crude incidence of type 2DM among UAE nationals who are overweight and obese was $1.49 \%$ per year during the 9-year study period. The overall incidence rate was 16.3 per 1000 person-years. The independent predictors for the development of type $2 \mathrm{DM}$ were age ( $\geq 44$ years) and obesity in women and pre-diabetes in men.
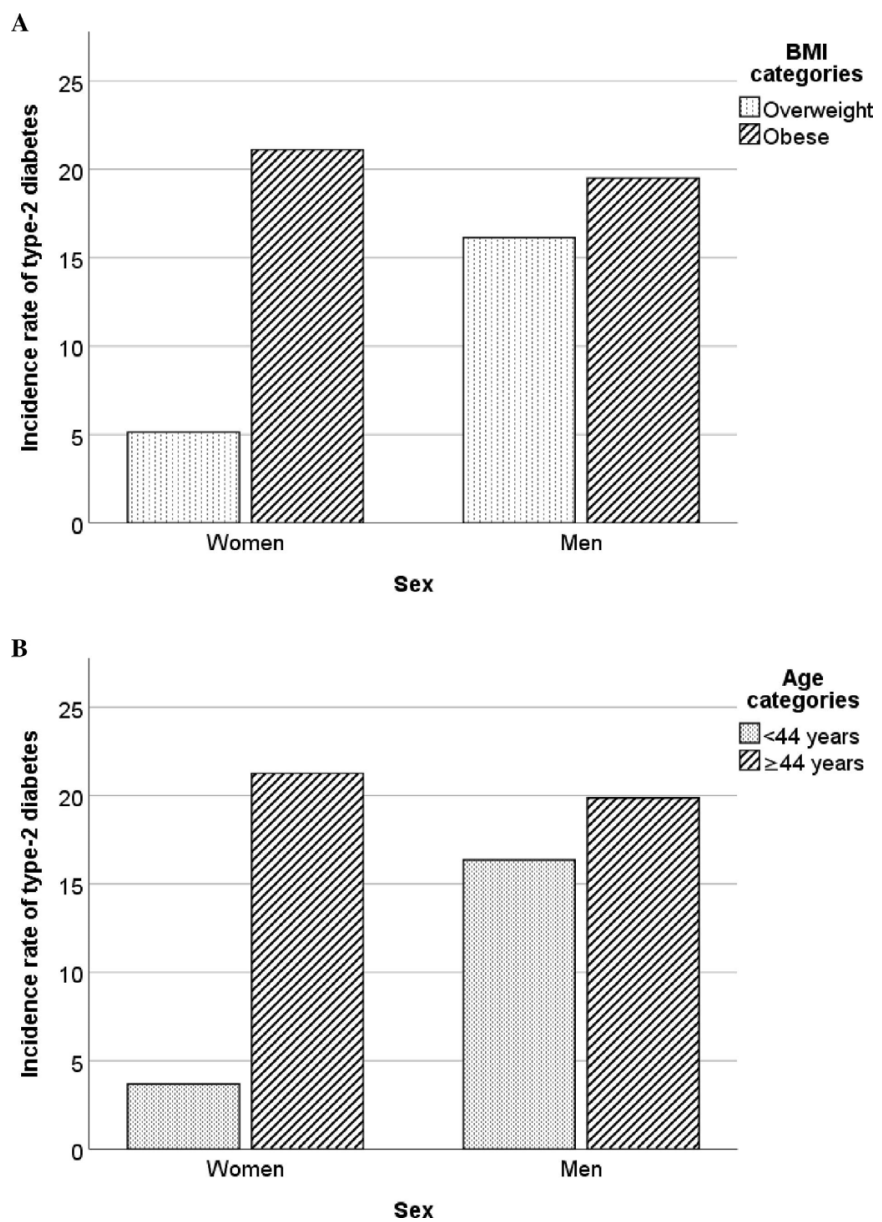

Figure 3 Sex-specific incidence rate of type 2 diabetes mellitus (cases/1000 person-years) stratified by BMI categories (A) and by age (B). BMI, body mass index.

\section{Incidence rates}

The incidence rates of type $2 \mathrm{DM}$ in high-risk populations differ worldwide. This difference is probably due to variations in insulin sensitivity related to the interaction between genetic and environmental factors among different ethnic and population groups globally. ${ }^{23}$ In a US study of predominantly overweight and obese AfricanAmerican women, the reported incidence rate of type $2 \mathrm{DM}$ was 15.2 per 1000 person-years ${ }^{24}$ and is comparable with our study. There has been only one other study that has assessed the incidence rate of type $2 \mathrm{DM}$ in the UAE. ${ }^{13}$ The study was conducted over 12 months in Ajman, one of the emirates in the UAE, and revealed that the incidence rate for type 2DM was 4.8 per 1000 person-years. However, this study cannot be directly compared with our study because it was conducted on the general population, and our study cohort comprised only overweight and obese UAE nationals.

\section{Risk factors}

This study revealed some interesting findings regarding the risk factors for developing type 2DM in the highrisk UAE population. Sex-specific incidence rates of type 2DM exhibited a female preponderance, particularly older women. Nevertheless, these results were not 
Table 2 Predictors of incident type 2 diabetes mellitus in the study population

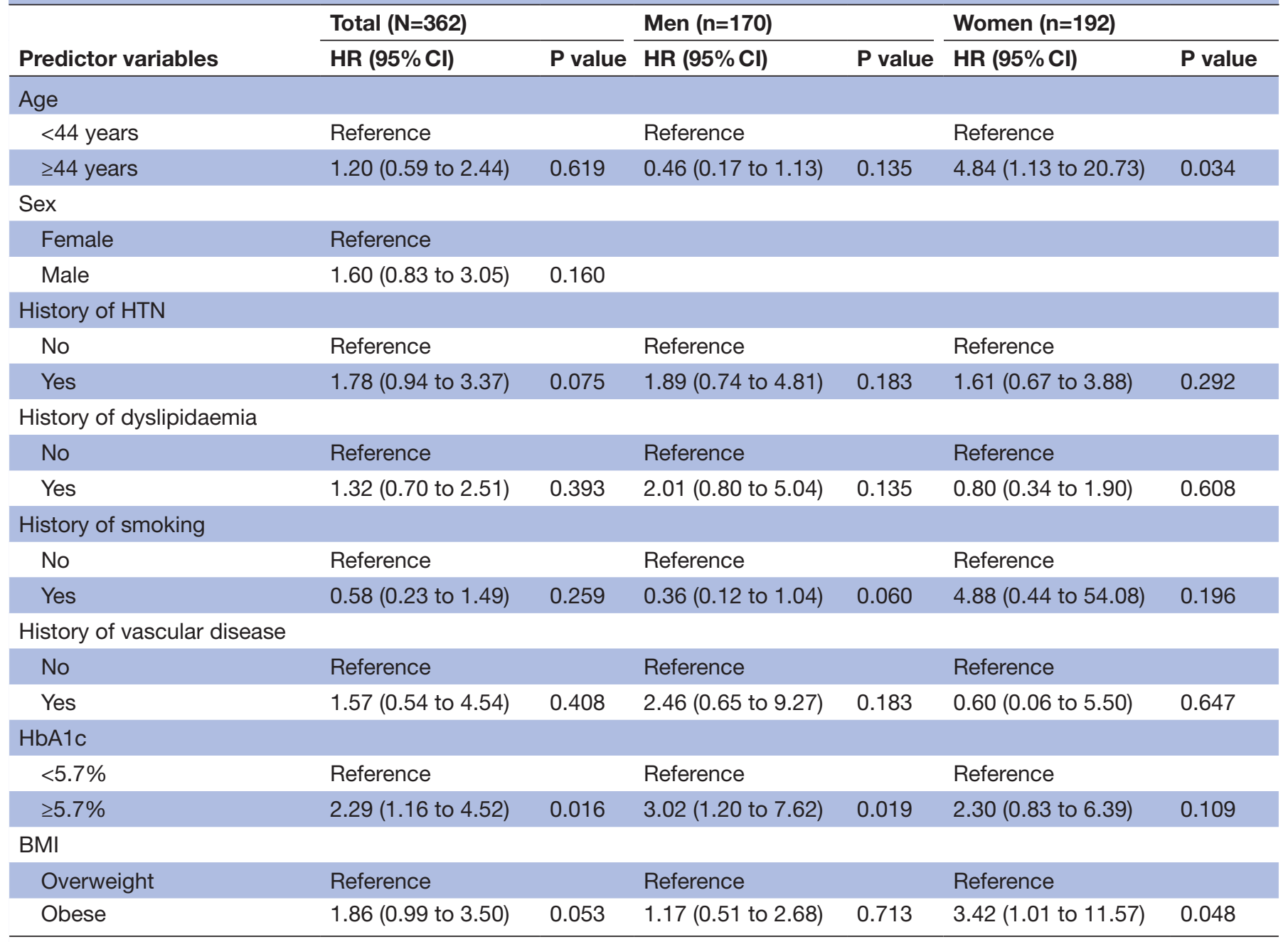

BMI, body mass index; HbA1c, glycated haemoglobin; HTN, hypertension.

unique and were also observed among the general population of the UAE. ${ }^{13}$ The higher incidence of type $2 \mathrm{DM}$ among older women may be attributable to the high prevalence of overweight and obesity, sedentary lifestyle, nutritional habits and early menopause witnessed in our population. ${ }^{25-28}$

Furthermore, individuals with high-normal HbAlc levels have a greater risk of developing type $2 \mathrm{DM}^{29}$ However, when we stratified our cohort by sex, the independent predictive property of the HbAlc level was only observed in men. An explanation for this finding could be the high prevalence of smoking history in men, as smoking has been shown to increase HbAlc levels in individuals without diabetes. ${ }^{30}$ Moreover, obesity in women was noted to be an independent risk predictor for type 2 DM. Studies have demonstrated that the risk of developing type $2 \mathrm{DM}$ is significantly higher in individuals with BMI $\geq 30 \mathrm{~kg} / \mathrm{m}^{2}$ compared with those with normal BMI. ${ }^{9}$ Therefore, interventions that promote weight loss and reduce BMI can reduce the risk of developing type $2 \mathrm{DM}$. Notably, an 8-week exercise intervention programme in a UAE student population demonstrated a significant reduction in BMI. ${ }^{31}$ In addition, other controlled intervention studies in high-risk populations ${ }^{32}{ }^{33}$ demonstrated a significant decrease in the risk of type $2 \mathrm{DM}$ consequent to $\mathrm{BMI}$ reduction.

\section{Clinical and public health implications}

In the UAE, much of the increase in type $2 \mathrm{DM}$ has occurred due to social and economic changes-from traditional, seminomadic lifestyle to sedentary, urban and high-income lifestyle. Consequently, the progression towards type $2 \mathrm{DM}$ and cardiovascular disease starts early in the UAE due to the high prevalence of childhood obesity. ${ }^{134}$ A 2015 study of Emirati children and adolescents with a BMI $\geq 25 \mathrm{~kg} / \mathrm{m}^{2}$ determined the prevalence of pre-diabetes and type $2 \mathrm{DM}$ to be $5.4 \%$ and $0.87 \%$, respectively. ${ }^{35}$ Therefore, reducing the burden of type $2 \mathrm{DM}$ in the UAE will require intensive population-wide interventions to promote regular physical activity and a healthy diet, ${ }^{33} 36$ particularly among the Emirati youth.

Furthermore, the results of this study highlight the need to focus on Emirati women as a specific target group for obesity prevention programmes. These programmes 
should begin in childhood because $21 \%$ are obese by the time they are 30 years of age.$^{26}$ In addition, it is imperative to have a multidisciplinary approach to address the high incidence of type $2 \mathrm{DM}$, where paediatricians, primary care providers, dietitians and specialists work collaboratively towards promoting weight reduction and maintaining a healthy BMI in our population.

\section{Strengths and limitations}

The strengths of this study include the long duration of follow-up for our representative sample of overweight and obese individuals in the second largest city in the Abu Dhabi Emirate of UAE. We used the anthropometric and laboratory data documented in patient charts instead of self-reported information and diagnostic codes for the classification of risk factors and identification of incident cases. In addition, HbAlc levels or physician diagnosis formed the basis to identify incident cases of type $2 \mathrm{DM}$ instead of fasting plasma glucose, which has more variability. ${ }^{3738}$

Nonetheless, this study had some limitations. Baseline data regarding family history of type $2 \mathrm{DM}$, history of gestational diabetes, physical activity and abdominal obesity were unavailable-all of which are well-researched risk factors for the development of DM. Nevertheless, a prospective study can provide more robust results. Furthermore, data on additional confounders, such as family history, changes in weight and physical activity, were unavailable for review. Finally, the subjects for this study were recruited from a single largest tertiary care hospital's ambulatory clinics; thus, our findings may not apply to the general UAE population.

\section{CONCLUSIONS}

The overall incidence rate of type $2 \mathrm{DM}$ in UAE nationals who are overweight and obese was 16.3 per 1000 personyears. Notably, pre-diabetes in men and obesity in women, particularly older women, were determined to be independent predictors for the development of incident type $2 \mathrm{DM}$. Hence, it is imperative to emphasise BMI reduction through lifestyle modifications in these high-risk groups.

Acknowledgements The authors would like to thank Shehab Majud for his help on the language in this manuscript.

Contributors DR conceived the study and its design, performed the literature search and drafted the initial manuscript. SA-S was involved in data management, statistical analysis, interpretation of data and critical review of the manuscript. $\mathrm{RDG}$ assisted in statistical analysis, contributed to the discussion, and reviewed and edited the manuscript. JA-K performed a critical review of the manuscript, was involved in data interpretation and also guided the research methodology. All authors read and approved the final manuscript.

Funding This work was supported by the College of Medicine and Health Sciences, United Arab Emirates University (no 31M325). The funders had no role in study design, data collection and analysis, decision to publish, or preparation of the manuscript.

Competing interests None declared.

Patient consent for publication Not required.

Ethics approval The Research and Ethics Board of Tawam Hospital and the United Arab Emirates University granted ethical approval to this study (CRD239/13).
Informed consent was waived because patient records and information were anonymised and deidentified before analysis.

Provenance and peer review Not commissioned; externally peer reviewed.

Data availability statement The data that support the findings of this study are available from the corresponding author, SA-S, upon reasonable request.

Open access This is an open access article distributed in accordance with the Creative Commons Attribution Non Commercial (CC BY-NC 4.0) license, which permits others to distribute, remix, adapt, build upon this work non-commercially, and license their derivative works on different terms, provided the original work is properly cited, appropriate credit is given, any changes made indicated, and the use is non-commercial. See: http://creativecommons.org/licenses/by-nc/4.0/.

ORCID iD

Saif Al-Shamsi http://orcid.org/0000-0001-9755-3493

\section{REFERENCES}

1 Saadi H, Carruthers SG, Nagelkerke N, et al. Prevalence of diabetes mellitus and its complications in a population-based sample in $\mathrm{Al}$ Ain, United Arab Emirates. Diabetes Res Clin Pract 2007;78:369-77.

2 Alzaabi A, Al-Kaabi J, Al-Maskari F, et al. Prevalence of diabetes and cardio-metabolic risk factors in young men in the United Arab Emirates: a cross-sectional national survey. Endocrinol Diabetes Metab 2019;2:e00081.

3 Eschwege E, Basdevant A, Crine A, et al. Type 2 diabetes mellitus in France in 2012: results from the ObEpi survey. Diabetes Metab 2015;41:55-61.

4 Caspard H, Jabbour S, Hammar N, et al. Recent trends in the prevalence of type 2 diabetes and the association with abdominal obesity lead to growing health disparities in the USA: an analysis of the NHANES surveys from 1999 to 2014. Diabetes Obes Metab 2018;20:667-71.

5 Tamayo T, Brinks R, Hoyer A, et al. The prevalence and incidence of diabetes in Germany. Dtsch Arztebl Int 2016;113:177-82.

6 Greiver M, Williamson T, Barber D, et al. Prevalence and epidemiology of diabetes in Canadian primary care practices: a report from the Canadian primary care sentinel surveillance network. Can J Diabetes 2014;38:179-85.

7 Center ICLD. UAE diabetes trends and numbers [Internet]. Available: http://www.icldc.ae/about-us/p/UAE-Diabetes-Trends [Accessed 19 Apr 2018].

8 World Health Organization (WHO). BMI classification [Internet], 2006. Available: https://www.who.int/news-room/fact-sheets/detail/ obesity-and-overweight [Accessed 18 Apr 2018].

9 Ganz ML, Wintfeld N, Li Q, et al. The association of body mass index with the risk of type 2 diabetes: a case-control study nested in an electronic health records system in the United States. Diabetol Metab Syndr 2014;6:50.

10 Al Dhaheri AS, Mohamad MN, Jarrar AH, et al. A cross-sectional study of the prevalence of metabolic syndrome among young female Emirati adults. PLoS One 2016;11:e0159378.

11 Loney T, Aw T-C, Handysides DG, et al. An analysis of the health status of the United Arab Emirates: the 'Big 4' public health issues. Glob Health Action 2013;6:20100.

12 Hajat C, Harrison O, Al Siksek Z. Weqaya: a population-wide cardiovascular screening program in Abu Dhabi, United Arab Emirates. Am J Public Health 2012;102:909-14.

13 Sreedharan J, Muttappallymyalil J, Al Sharbatti S, et al. Incidence of type 2 diabetes mellitus among Emirati residents in Ajman, United Arab Emirates. Korean J Fam Med 2015;36:253-7.

14 Dhabi SCA. Statistics center. In: SCAD [Internet], 2017. Available: https://www.scad.gov.abudhabi/Release\%20Documents/ Statistical\%20Yearbook\%20-\%20Population\%20-\%20EN.pdf [Accessed 19 Apr 2018].

15 Razzak H, El-Metwally A, Harbi A, et al. The prevalence and risk factors of obesity in the United Arab Emirates. Saudi Journal of Obesity 2017;5:57.

16 Levin A, Stevens PE, Bilous RW, et al. Kidney disease: improving global outcomes (KDIGO) CKD work group. KDIGO 2012 clinical practice guideline for the evaluation and management of chronic kidney disease. Kidney Int Suppl 2013;3:1-150.

17 National High Blood Pressure Education Program. The seventh report of the joint National Committee on prevention, detection, evaluation, and treatment of high blood pressure. Bethesda (MD: National heart, lung, and blood Institute (US), 2004. http://www.ncbi. nlm.nih.gov/books/NBK9630/ 
18 Expert panel on detection, evaluation, and treatment of high blood cholesterol in adults. executive summary of the third report of the National cholesterol education program (NCEP) expert panel on detection, evaluation, and treatment of high blood cholesterol in adults (adult treatment panel III). JAMA 2001;285:2486-97.

19 American Diabetes Association. Diagnosis and classification of diabetes mellitus. Diabetes Care 2010;33 Suppl 1:S62-9.

20 The American Diabetes Association, European Association for the Study of Diabetes, International Federation of Clinical Chemistry and Laboratory Medicine, International Diabetes Federation. Consensus statement on the worldwide standardization of the hemoglobin A1c measurement. Diabetes Care 2007;30:2399-400.

21 Rosner B. Fundamentals of biostatistics. 7th edn. Boston: Cengage Learning, Inc, 2010.

22 International Diabetes Federation. IDF diabetes atlas. 8th edn Brussels,Belgium: International Diabetes Federation, 2017.

23 Dagenais GR, Gerstein HC, Zhang X, et al. Variations in diabetes prevalence in low-, middle-, and high-income countries: results from the prospective urban and rural epidemiological study. Diabetes Care 2016;39:780-7.

24 Krishnan S, Rosenberg L, Djoussé L, et al. Overall and central obesity and risk of type 2 diabetes in U.S. black women. Obesity 2007;15:1860-6.

25 Sheikh-Ismail LI, Henry CJK, Lightowler HJ, et al. Prevalence of overweight and obesity among adult females in the United Arab Emirates. Int J Food Sci Nutr 2009;60:26-33.

26 Carter AO, Saadi HF, Reed RL, et al. Assessment of obesity, lifestyle, and reproductive health needs of female citizens of al Ain, United Arab Emirates. J Health Popul Nutr 2004;22:75-83.

27 Trainer S. Negotiating weight and body image in the UAE: strategies among young Emirati women. Am J Hum Biol 2012;24:314-24.

28 Rizk DE, Bener A, Ezimokhai M, et al. The age and symptomatology of natural menopause among United Arab Emirates women. Maturitas 1998;29:197-202.
29 Bonora E, Kiechl S, Mayr A, et al. High-normal HbA1c is a strong predictor of type 2 diabetes in the general population. Diabetes Care 2011;34:1038-40.

30 Clair C, Bitton A, Meigs JB, et al. Relationships of cotinine and selfreported cigarette smoking with hemoglobin A1c in the U.S.: results from the National health and nutrition examination survey, 19992008. Diabetes Care 2011;34:2250-5.

31 Dalibalta S, Mirshafiei F, Davison G. Exercise intervention on cardiovascular disease risk factors in a university population in the United Arab Emirates. Int J Adolesc Med Health 2017;30:ija $\mathrm{mh}-2016-0132$.

32 Lindström J, Eriksson JG, Valle TT, et al. Prevention of diabetes mellitus in subjects with impaired glucose tolerance in the Finnish diabetes prevention study: results from a randomized clinical trial. $J$ Am Soc Nephrol 2003;14:108S-13.

33 Penn L, White M, Lindström J, et al. Importance of weight loss maintenance and risk prediction in the prevention of type 2 diabetes: analysis of European diabetes prevention study RCT. PLoS One 2013;8:e57143

34 Al Junaibi A, Abdulle A, Sabri S, et al. The prevalence and potential determinants of obesity among school children and adolescents in abu dhabi, United Arab Emirates. Int J Obes 2013;37:68-74.

35 Al Amiri E, Abdullatif M, Abdulle A, et al. The prevalence, risk factors, and screening measure for prediabetes and diabetes among Emirati overweight/obese children and adolescents. BMC Public Health 2015;15:1298.

36 Souto SB, Souto EB, Braga DC, et al. Prevention and current onset delay approaches of type 2 diabetes mellitus (T2DM). Eur J Clin Pharmacol 2011;67:653-61.

37 Sacks DB. A1C versus glucose testing: a comparison. Diabetes Care 2011;34:518-23.

38 Selvin E, Crainiceanu CM, Brancati FL, et al. Short-term variability in measures of glycemia and implications for the classification of diabetes. Arch Intern Med 2007;167:1545-51. 